\title{
Ortaokul Öğrencilerinin Bilişim Teknolojilerinden Yararlanma Düzeylerinin Farklı Değişkenler Açısından İncelenmesi
}

\author{
Enes Abdurrahman BíLGíN \\ Van Yüzüncü Y1l Üniversitesi, Eğitim Fakültesi, Matematik Öğretmenliği Bölümü Van, Türkiye \\ Orcid: 0000-0003-3003-9259, enesbilgin@yyu.edu.tr
}

\begin{abstract}
Özet
Günümüzde gelişen ve yaygınlaşan teknolojik imkânlar sayesinden bilişim teknolojileri öğretimin her düzeyinde öğrenciler ve öğretmenler tarafından yaygın biçimde kullanılmaya başlanmıştır. Özellikle somutlaştırmanın büyük öneme sahip olduğu ortaokul öğrencileri açsından bu teknolojiler büyük önem kazanmaktadır. Bu bağlamda bu çalışmada ortaokul öğrencilerin bilişim teknolojilerinde yararlanma düzeylerinin incelenmesi amaçlanmıştır. Bu amaca yönelik olarak nicel araştırma yöntemlerinden olan tarama modeli tercih edilmiştir. Araştırmada veri toplama aracı olarak Özmusul (2011) tarafından ortaokul öğrencilerine yönelik geliştirilen "Bilişim Teknolojilerinden Yararlanma Ölçeği” kullanılmıştır. Ölçeğe ilişkin güvenirlik katsayısı 0.85 olarak bildirilmiştir ve dörtlü likert tipine sahiptir. Diğer taraftan katılımcılar uygun örnekleme yöntemi ile belirlenen ve 2019-2020 eğitim- öğretim yılı güz döneminde Van iline bağlı Erciş ilçesinde ortaokullarda eğitim gören 59 öğrenciden ibarettir. Araştırmada öğrencilerin bilişim teknolojilerinden yararlanma düzeylerinin cinsiyet, sınıf, genel başarı düzeyi, anne- baba eğitim düzeyi ve internete erişim gibi faktörlere göre nasıl bir değişim gösterdiği de istatistiksel olarak incelenmiştir. Verilerin analizi sürecinde normallik testleri, Mann Whitney U testi ve tek yönlü varyans analizi testlerinden faydalanılmış ve $\% 5$ anlamlılık düzeyine göre sonuçlar yorumlanmıştır. Elde edilen bulgulara göre öğrencilerin genel olarak \%73 oranında bilişim teknolojilerinden yaralandıkları sonucuna ulaşılmıştır. Ayrıca bu düzeylerin öğrencilerin genel not ortalamalarına, anne-baba eğitim düzeylerine ve incelenen diğer değişkenlere göre anlamlı biçimde değişmediği ancak kız öğrencilerin anlamlı biçimde erkek öğrencilerden daha yüksek kullanım düzeyine sahip oldukları sonucuna ulaşılmıştır.
\end{abstract}

Anahtar Kelimeler: Bilişim Teknolojileri, ortaokul öğrencileri, Van ili

\section{Investigation of Secondary School Students' Utilization Levels of Information Technologies in Terms of Different Variables}

\begin{abstract}
Nowadays, thanks to the developing and widespread technological opportunities, information technologies have begun to be widely used by students and teachers at all levels of education. These technologies are especially important for secondary school students, for whom concretization is of great importance. In this context, this
\end{abstract}

Year 5/ 2021, Volume-5, Issue-2 | www.ispecjournal.org 
study aimed to examine the utilization levels of middle school students in information technologies. For this purpose, scanning model, which is one of the quantitative research methods, was preferred. The "Information Technology Utilization Scale" developed by Özmusul (2011) for secondary school students was used as a data collection tool in the study. The reliability coefficient for the scale was reported as 0.85 and it has a four-point Likert type. On the other hand, the participants consisted of 59 students who were determined by the appropriate sampling method and studying at secondary schools in Erciş district of Van province in the fall semester of the 2019-2020 academic year. In the study, how the students' level of using information technologies differ according to factors such as gender, class, general success level, parental education level and internet access was also analyzed statistically. During the data analysis process, normality tests, , Mann Whitney U test and one-way analysis of variance tests were used and the results were interpreted according to the 5\% significance level. According to the findings, it was concluded that the students generally benefited from information technologies at a rate of $73 \%$. In addition, it was concluded that these levels did not change significantly according to the students 'general grade averages, parents' education levels and other variables examined, but female students had a significantly higher level of use than male students.

Keywords: Information Technologies, secondary school students, Van province.

\section{GíRiş}

Bilişim teknolojileri (IT) (Info Communication Technologies) insanlığın tarih boyunca biriktirdiği bilgi birikiminin bir devamı niteliğindedir ve günümüzde içinde yaşadığımız bilgi çağına kadar ulaşılan tüm bilimsel ve teknolojik gelişmelerin bir sonucu olarak görülmektedirler (Yeşilorman ve Koç, 2014). Bilgi teknolojisinde akla, ilk olarak bilgisayarlar gelmektedir ve bilgisayarlar sayesinde bireyler bilgileri, istenildiği kadar depolayabilmekte, işleyebilmekte ve buradan yeni bilgiler üretebilmektedir (Sarıöz, 2012). Kuşkusuz bu süreçte eğitim öğretim faaliyetlerinde de bilişim teknolojileri kullanılmaktadır. Literatürde önceleri "Bilgisayar destekli eğitim" olarak kullanılan bu kavram gelişen teknolojik araçların artması ile "Teknoloji destekli eğitim” şekline dönüşmüştür (Baysan, Bayra ve Demirkan, 2018). Genel olarak bilişim teknolojilerinin eğitimde kullanımı öğrenciler ve öğretmenler için avantajlar sağlamaktadır. Özellikle öğrenciler, amaca yönelik tasarlanmış özel öğretim yöntemleri ile alıştırmalar, uygulamalar, hesaplamalar ve konu tekrarları sayesinde kısa sürede çalışma ortamına girebilmekte ve gerektiğinde anında dönüt alabilmektedirler. Benzer şekilde geliştirilen uygulamalar ile zeka türü ve seviyesi farklı olan öğrenciler için de kolaylıklar ve ayrıcalıklar sunulabilmektedir (Engin, Tösten ve Kaya, 2010). Diğer taraftan özellikle ortaokul düzeyindeki öğrenciler için teknolojinin sunduğu görselliğin öğrencileri motive etmesi ve ilgilerini çekmesi büyük öneme sahiptir. Örneğin

Year 5/ 2021, Volume-5, Issue-2 | WWW.ispecjournal.org 
soyut kavramlardan oluşan matematik derslerinde bu tarz somutlaştırmalar sayesinde kavramların mantığının kolayca öğrenilmesi sağlanabilmektedir. Ayrıca teknoloji sayesinde işlemlerle zaman kaybetmeden üst düzey düşünme becerileri desteklenerek daha iyi öğrenmeler sağlamaktadır (Çetin ve Mirasyedioğlu, 2019). Literatürde yer alan tüm bu incelemelerden anlaşıldığı üzere teknoloji destekli öğretimin öğrencilere büyük faydaları bulunmaktadır.

Diğer taraftan günümüzde eğitim sistemleri, bilgiye ulaşabilen, kullanabilen, iletebilen, üretebilen, teknolojiyi kullanabilen ve kendi kendisine öğrenebilen bireylerin yetiştirilmeyi amaçlamaktadırlar. Bu nedenle birçok ülkede okullar öğrencilerin bilgi ve bilgisayar okuryazarlığı becerilerinin geliştirilmesini zorunlu hale getirmiştir (Akkoyunlu ve Kurbanoğlu, 2003). Dolayısı ile günümüz toplumları için birer mecburiyet halini alan uzaktan eğitim (Bakioğlu ve Çevik, 2020) ve mobil öğrenme gibi teknolojik imkânların aktif kullanıcıları durumunda olan öğrencilerin bu araçları kullanma düzeylerinin araştırılması büyük önem taşımaktadır.

$\mathrm{Bu}$ bağlamda bu çalışmada ortaokul öğrencilerinin bilişim teknolojilerinden yararlanma düzeylerinin incelenmesi amaçlanmıştır. Ayrıca bu düzeylere öğrencilerin cinsiyetlerinin, sınıf seviyelerinin, anne ve baba eğitim durumlarının nasıl bir etkisinin bulunduğu da incelenmiştir. Dolayısı ile çalışmanın araştırma soruları;

- Ortaokul öğrencilerinin bilişim teknolojilerinden yararlanma düzeylerini nedir?

- Ortaokul öğrencilerinin bilişim teknolojilerinden yararlanma düzeylerine cinsiyet, sınıf, not ortalaması, anne ve baba eğitim düzeyi gibi faktörlerin etkisi var mıdır? şeklinde belirlenmiştir.

\section{YÖNTEM}

\section{1. Araştırma deseni}

Araştırmanın amacına uygun olarak karşılaştırma türünde ilişkisel tarama modeli seçilmiştir. $\mathrm{Bu}$ modelde incelenen değişken, bağımsız değişkenin alt gruplarına göre kıyaslanarak aralarında bir farklılaşma olup olmadığı araştırılmaktadır. Bu sayede bağımsız değişken ile bağımlı değişken arasındaki ilişkiler açığa çıkartılmaktadır (Karasar. 1999). Dolayısıyla ortaokul öğrencilerinin Bilişim teknolojilerinden yararlanma düzeylerinin çeşitli demografik özelliklerden nasıl etkilendiğinin araştırılması amaçlanmıştır. bu amaca yönelik olarak Öğrencilerin Cinsiyet sınıf not ortalaması anne ve baba eğitim düzeyi Faktörlerine yönelik 
bilgileri toplanmış aynı zamanda Bilişim teknolojilerinden yararlanma düzeyleri bu faktörlere ait alt grupların kıyaslanması yoluyla ortaya konmuştur.

\section{2. Çalışma Grubu}

Araştırmanın örnekleminin 2019-2020 eğitim- öğretim yılının birinci döneminde Van iline bağlı Erciş ilçe merkezindeki ortaokullarında eğitim gören farklı sınıf seviyelerinde 59 öğrenci oluşturmaktadır. Araştırmanın evrenini Van ilinde öğrenim gören tüm ortaokul öğrencileri oluşturmaktadır Diğer taraftan çalışmaya katılan öğrenciler uygun örnekleme yöntemi ile belirlenmiş ve araştırmacının ulaşabildiği öğrencilerle yürütülmüştür Diğer taraftan öğrenciler genel olarak evren'i temsil edebilecek düzeyde Öğrenciler olmasına dikkat edilmiştir. Katılımcıların \%34'ü kız \%66'sı erkek öğrencilerden oluşmaktadır. Ayrıca \% 20'si 6. sınıf \%25'i 7-sınıf \%54'ü 8 sınıf öğrencisidir. Diğer taraftan katılımcıların babalarının eğitim düzeyleri incelendiğinde \%15'i ilkokul \%37'si ortaokul \%27'si lise ve \%20'si de üniversite mezunudur. Annelerinin eğitim düzeyi incelendiğinde ise \%44'ünün okuma yazması olmadığı \%20'sinin ilkokul mezunu olduğu \%19'unun ortaokul \%10'unun lise \%7'sinin üniversite mezunu olduğu görülmüştür. Son olarak öğrencilerinin genel not ortalamaları 50- 65 aralığında olan öğrencilerin oranı \%12, 65-80 aralığında olan öğrencilerin oranı \%31, 80-100 aralığında olan öğrencilerin oranı ise \%58 dir.

\subsection{Veri Toplama Araçları ve Verilerin Çözümlenmesi}

Araştırmada veri toplama aracı olarak Özmusul (2011) tarafından geliştirilen ve 18 maddeden oluşan "Bilişim Teknolojilerinden Yararlanma Ölçeği” kullanılmıştır. Ölçek "hiçbir zaman”, "bazen", "genellikle" ve "her zaman" şeklinde dörtlü Likert tipinde seçenekler ile hazırlanmıştır. Ölçeğin Spearman Brown güvenirlik katsayısı 0.7962 ve Cronbach's Alpha güvenirlik katsayısı 0.857 olarak hesaplanmıştır. Araştırma kapsamında toplanan verilere ilişkin betimsel istatistikler hesaplanmıştır. Bunun yanı sıra ölçek maddelerine verilen yanıtların yüzdelik dağılımları da sunulmuştur. Araştırmada verinin yapısının tespit edilebilmesi için öncelikle normallik testleri yapılmış bu testlerin sonucuna göre parametrik olmayan testlerden Mann-Whitney u testi ile parametrik testlerden Anova testi kullanılmıştır. Analiz bulguları $\% 5$ anlamlılık düzeyine göre yorumlanmıştır. 


\section{BULGULAR}

$\mathrm{Bu}$ bölümde toplanan veriler 1şığında elde edilen bulgular sunulmuştur. Diğer taraftan öğrencilerin demografik gruplara dağılımları ve bu gruplara ait teknolojiden yararlanma düzeylerine ilişkin ölçek toplam puanları, başarı yüzdeleri, standart sapmaları ve standart hataları Tablo 1'de sunulmuştur.

Tablo 1. Betimsel İstatistikler

\begin{tabular}{|c|c|c|c|c|c|c|c|}
\hline Faktör & Grup & $\mathbf{N}$ & $\%$ & $\begin{array}{l}\text { Puan } \\
\text { Ort. }\end{array}$ & $\begin{array}{l}\text { \% Başarı } \\
\text { Oranı }\end{array}$ & Stn. Sap. & Stn. Hata \\
\hline \multirow[t]{2}{*}{ Cinsiyet } & $\mathrm{K}_{1 \mathrm{Z}}$ & 20 & 34 & 54,00 & $\% 75$ & 9,10 & 2,04 \\
\hline & Erkek & 39 & 66 & 51,10 & $\% 71$ & 9,15 & 1,47 \\
\hline \multirow[t]{3}{*}{ Sinıf } & 6.sinif & 12 & 20 & 49,33 & $\% 69$ & 6,97 & 2,01 \\
\hline & 7.sinif & 15 & 25 & 54,20 & $\% 75$ & 6,87 & 1,77 \\
\hline & 8.sinif & 32 & 54 & 52,13 & $\% 72$ & 10,65 & 1,88 \\
\hline \multirow[t]{3}{*}{ Not ortalaması } & $50-65$ & 7 & 12 & 53,29 & $\% 74$ & 2,98 & 1,13 \\
\hline & $65-80$ & 18 & 31 & 51,39 & $\% 71$ & 7,54 & 1,78 \\
\hline & $80-100$ & 34 & 58 & 52,21 & $\% 73$ & 10,77 & 1,85 \\
\hline \multirow{4}{*}{$\begin{array}{l}\text { Baba Eğitim } \\
\text { Düzeyi }\end{array}$} & İlkokul & 9 & 15 & 48,56 & $\% 67$ & 8,59 & 2,86 \\
\hline & Ortaokul & 22 & 37 & 50,95 & $\% 71$ & 9,33 & 1,99 \\
\hline & Lise & 16 & 27 & 54,50 & $\% 76$ & 8,97 & 2,24 \\
\hline & Üniversite & 12 & 20 & 53,58 & $\% 74$ & 9,45 & 2,73 \\
\hline \multirow[t]{5}{*}{$\begin{array}{l}\text { Anne Eğitim } \\
\text { Düzeyi }\end{array}$} & $\begin{array}{l}\text { Okuma } \\
\text { yazma yok }\end{array}$ & 26 & 44 & 53,50 & $\% 74$ & 8,95 & 1,75 \\
\hline & İlkokul & 12 & 20 & 48,58 & $\% 67$ & 5,35 & 1,54 \\
\hline & Ortaokul & 11 & 19 & 51,73 & $\% 72$ & 8,80 & 2,65 \\
\hline & Lise & 6 & 10 & 56,33 & $\% 78$ & 15,55 & 6,35 \\
\hline & Üniversite & 4 & 07 & 48,00 & $\% 67$ & 8,04 & 4,02 \\
\hline
\end{tabular}

Tablo 1'de yer alan bilgiler incelendiğinde cinsiyet faktörü incelendiğinde Kız grubuna ilişkin ölçek ortalaması 54( \%75 başarı) puan iken standart sapması 9,1 puandır. Erkek grubu ise kız grubuna göre daha az başarı göstererek ölçek ortalaması 51,1( \%71 başarı) puan iken standart sapması 9,15olarak hesaplanmıştır. Sınıf değişkeni incelendiğinde ise 6.sınıf grubu ortalama puan 49,33( \%69 başarı) puan ile en başarısız grup iken 7.sınıf için ise ortalama 54,2( \%75 başarı) puan ile en başarılı grup olarak karşımıza çıkmaktadır. Diğer taraftan, 8.sınıf için ortalama 52,13( \%72 başarı) puan olduğu görülmektedir. Not ortalaması dikkate alındığında ise 50-65 grubu 53,29( \%74 başarı) puan ile en yüksek ölçek ortalamasına sahiptir ve 65-80 grubu ise en düşük puana 51,39( \%71 başarı) ortalama ile sahiptir. Son olarak, 80-100 grubuna ilişkin ölçek ortalaması 52,21( \%73 başarı) olarak hesaplanmıştır. Baba eğitim düzeyi incelendiğinde ise ilkokul grubuna ilişkin ölçek ortalaması 48,56( \%67 başarı) puan ile en başarısız grubu oluştururken Lise grubu ise 54,5( \%76 başarı) puan ile en yüksek grubu oluşturmaktadır. Annelerin eğitim düzeylerine göre puanlar incelendiğinde ise lise grubuna 
ilişkin ölçek ortalaması 56,33( \% 078 başarı) puan ile en başarılı grubu oluştururken üniversite grubu 48 ( $\% 67$ başarı) puan ile en başarısız grubu oluşturmaktadır.

Tüm katılımcıların ölçek puanlarına ilişkin ortalama puan 52.8 olarak hesaplanmıştır. Ayrıca standart sapma 9,08 ve standart hata ise 1.17 şeklinde hesaplanmıştır. Ölçekten alınabilecek en yüksek puanın 72 olduğu göz önünde bulundurulduğunda tüm öğrencilerin bilişim teknolojilerini kullanma oranlarının \%73.3 oranında olduğu tespit edilmiştir.

Katılımcıların ölçek maddelerine verdikleri yanıtların detaylı biçimde incelenmesi amacıyla bazı maddelere ilişkin yanıtların yüzdelik dağılımları Tablo 2'de sunulmuştur.

Tablo 2. Yanıtların dağılımı

\begin{tabular}{|c|c|c|c|c|}
\hline Maddeler & 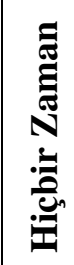 & 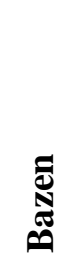 & 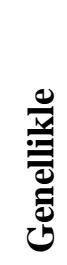 & 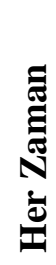 \\
\hline 1. Bilgi edinmek için bilişim teknolojilerinden yararlanırım & 00 & 20 & 28 & 52 \\
\hline $\begin{array}{l}\text { 2. Bilgi dağarcığımı(düzeyimi) artırmak için bilişim teknolojilerinden } \\
\text { yararlanırım }\end{array}$ & 02 & 40 & 33 & 25 \\
\hline $\begin{array}{l}\text { 3. Öğretmenlerimizin verdiği ödevleri yaparken bilişim teknolojilerinden } \\
\text { yararlanırım }\end{array}$ & 05 & 47 & 23 & 25 \\
\hline $\begin{array}{l}\text { 6. Kendime faydalı olacağını düşündüğüm bir konuyu araştırırken } \\
\text { yararlanırım. }\end{array}$ & 02 & 20 & 32 & 47 \\
\hline 7. Merak ettiğim bir konuyu araştırırken bilișim teknolojilerinden yararla & 03 & 10 & 33 & 53 \\
\hline
\end{tabular}

Tablo 3. Yanıtların dağılımı

\begin{tabular}{|l|c|c|c|c|}
\hline $\begin{array}{l}\text { 8. Bilmediğim olayları araştırırken bilişim teknolojilerinden } \\
\text { yararlanırım. }\end{array}$ & 05 & 18 & 25 & 52 \\
\hline 9. Birinden haber almak için bilişim teknolojilerinden yararlanırım. & 02 & 12 & 30 & 57 \\
\hline $\begin{array}{l}\text { 10. Birine mesaj göndermek istediğimde bilişim teknolojilerinden } \\
\text { yararlanırım. }\end{array}$ & 03 & 13 & 22 & 62 \\
\hline 11. Birine haber vermek için bilişim teknolojilerinden yararlanırım & 02 & 17 & 30 & 52 \\
\hline 14. Düşüncelerimi ifade ederken bilişim teknolojilerinden yararlanırım & 38 & 33 & 17 & 12 \\
\hline 15. Düşüncelerimi paylaşırken bilişim teknolojilerinden yararlanırım & 37 & 32 & 15 & 17 \\
\hline $\begin{array}{l}\text { 16. Eğlenceli vakitler geçirmek istediğimde bilişim teknolojilerinden } \\
\text { yararlanırım }\end{array}$ & 12 & 30 & 32 & 27 \\
\hline
\end{tabular}

Tablo 2'de yer alan maddelere verilen yanıtların dağılımları incelendiğinde öğrencilerin "Kendime faydalı olacağını düşündüğüm bir konuyu araştırırken yararlanırım.” maddesine büyük çoğunluğun olumlu yanıt verdiği anlaşılmaktadır. Benzer şekilde "Birinden haber 
almak için bilişim teknolojilerinden yararlanırım.” maddesine verilen yanıtların büyük çoğunluğu da olumludur. Diğer taraftan "Düşüncelerimi ifade ederken bilişim teknolojilerinden yararlanırım" ve "Düşüncelerimi paylaşırken bilişim teknolojilerinden yararlanırım" maddelerine genellikle düşük düzeyde katılım olmuştur.

Öğrencilerin incelenen faktörlere ilişkin alt gruplar bağlamında karşılaştırılmalarına yönelik istatistiksel yöntemlerin belirlenmesi amacıyla normallik testleri gerçekleştirilmiştir.

Tablo 3. Normallik testi sonuçları

\begin{tabular}{|c|c|c|c|c|c|c|c|}
\hline \multirow{2}{*}{ Faktör } & \multirow{2}{*}{ Grup } & \multicolumn{3}{|c|}{ Kolmogorov-Smirnov } & \multicolumn{3}{|c|}{ Shapiro-Wilk } \\
\hline & & İst. & $\mathrm{sd}$ & $\mathrm{p}$ & İst. & $\mathrm{sd}$ & $\mathrm{p}$ \\
\hline \multirow[t]{3}{*}{ Sinıf } & 6.Sinif & .153 & 12 & .200 & .909 & 12 & .210 \\
\hline & 7.Sinif & .109 & 16 & .200 & .975 & 16 & .909 \\
\hline & 8.Sinif & .136 & 32 & .139 & .942 & 32 & .085 \\
\hline \multirow[t]{3}{*}{ Not } & $2-3$ & .268 & 8 & .095 & .945 & 8 & .663 \\
\hline & $3-4$ & .135 & 18 & .200 & .926 & 18 & .165 \\
\hline & $4-5$ & .072 & 34 & .200 & .979 & 34 & .734 \\
\hline \multirow[t]{2}{*}{ Cinsiyet } & $\mathrm{K}_{1 \mathrm{Z}}$ & .209 & 20 & $.023 *$ & .884 & 20 & $.021 *$ \\
\hline & Erkek & .143 & 40 & $.039 *$ & .907 & 40 & $.003 *$ \\
\hline \multirow{4}{*}{$\begin{array}{l}\text { Baba eğitim } \\
\text { durumu }\end{array}$} & İlkokul & .206 & 9 & .200 & .918 & 9 & .372 \\
\hline & Ortaokul & .130 & 22 & .200 & .973 & 22 & .775 \\
\hline & Lise & .211 & 17 & $.043 *$ & .922 & 17 & .162 \\
\hline & Üniversite & .191 & 12 & .200 & .942 & 12 & .525 \\
\hline \multirow{4}{*}{$\begin{array}{l}\text { Anne eğitim } \\
\text { durumu }\end{array}$} & İlkokul & .118 & 26 & .200 & .967 & 26 & .537 \\
\hline & Ortaokul & .138 & 12 & .200 & .938 & 12 & .478 \\
\hline & Lise & .223 & 12 & .102 & .892 & 12 & .124 \\
\hline & Üniversite & .257 & 6 & .200 & .881 & 6 & .276 \\
\hline
\end{tabular}

Tablo 3'de yer alan Kolmogorov-Smirnov ve Shapiro-Wilk testleri incelendiğinde cinsiyet faktörü dışındaki tüm faktörlerin normallik şartını sağladıkları görülmüştür. Dolayısı ile cinsiyet düzeylerinin kıyaslanmasında Mann Whitney $U$ testi kullanılırken, Sınıf, Not ortalaması ve anne- baba eğitim düzeylerinin kıyaslanması amaciyla Anova testlerinden faydalanılmıştır.

Tablo 4. Cinsiyet Faktörü

\begin{tabular}{|l|l|l|l|l|l|l|l|}
\hline Grup & N & Rank Ort. & Rank Top. & U & Z & p & Cohen's d \\
\hline K1z & 20 & 36,65 & 733,00 & 257,000 & $-2,133$ &, 033 & 0.577 \\
\hline Erkek & 39 & 26,59 & 1037,00 & & & & \\
\hline Total & 59 & & & & & & \\
\hline
\end{tabular}

Tablo 4'de yer alan Mann Whitney U testi sonuçlarına göre cinsiyet faktörü açısından gruplar arasında istatistiksel olarak anlamlı farklılık olduğu tespit edilmiştir. $(U=257, p<0.05$, Year 5/ 2021, Volume-5, Issue-2 | WWW.ispecjournal.org 
$\mathrm{d}=0,577)$. Bu sonuca göre ortaokul öğrencileri için kızların bilişim teknolojilerinden yararlanma düzeylerinin erkeklerden anlamlı biçimde yüksek olduğu anlaşılmaktadır.

Diğer taraftan sınıf faktörünün öğrencilerin bilişim teknolojilerini kullanma düzeylerine etkisinin incelenmesi amacıyla gerçekleştirilen Anova testine yönelik sonuçlar Tablo 5'de sunulmuştur.

Tablo 5. Sinıf Faktörü

\begin{tabular}{|l|l|l|l|l|l|}
\hline Varyans Kay. & Kareler Top. & sd & Kareler Ort. & F & p \\
\hline Grup & 158,010 & 2 & 79,005 &, 939 &, 397 \\
\hline Hata & 4710,567 & 56 & 84,117 & & \\
\hline Toplam & 4868,576 & 58 & & & \\
\hline
\end{tabular}

Tablo 5'de yer alan Anova testi sonuçlarına göre sınıf faktörü açısından gruplar arasında istatistiksel olarak anlamlı farklılık bulunmadığı tespit edilmiştir. $(F(2,56)=0.939, p>0.05) . B u$ sonuca göre 6., 7. ve 8. sınıf ortaokul öğrencilerinin bilişim teknolojilerinden yararlanma düzeyleri arasında herhangi bir farklılık olmadı̆̆ı dolayısı ile sınıf faktörünün ölçek puanlarına bir etkisinin bulunmadığı söylenebilir. Diğer taraftan not faktörünün öğrencilerin bilişim teknolojilerini kullanma düzeylerine etkisinin incelenmesi amacıyla gerçekleştirilen Anova testine yönelik sonuçlar Tablo 6'da sunulmuştur.

Tablo 6. Bașarı / Not Faktörü

\begin{tabular}{|l|l|l|l|l|l|}
\hline Varyans Kay. & Kareler Top. & sd & Kareler Ort. & F & p \\
\hline Grup & 19,311 & 2 & 9,656 &, 112 &, 895 \\
\hline Hata & 4849,265 & 56 & 86,594 & & \\
\hline Toplam & 4868,576 & 58 & & & \\
\hline
\end{tabular}

Tablo 6'de yer alan Anova testi sonuçlarına başarı notu açısından gruplar arasında istatistiksel olarak anlamlı farklılık bulunmadığı tespit edilmiştir. $(\mathrm{F}(2,57)=0.112, \mathrm{p}>0.05)$. Bu sonuca göre ortaokul öğrencilerinin başarı notu ortalamaları bilişim teknolojilerinden yararlanma düzeyleri arasında herhangi bir farklılık olmadığı dolayısı ile başarı notu faktörünün ölçek puanlarına bir etkisinin bulunmadığı söylenebilir. Diğer taraftan anne eğitimi faktörünün öğrencilerin bilişim teknolojilerini kullanma düzeylerine etkisinin incelenmesi amaciyla gerçekleştirilen Anova testine yönelik sonuçlar Tablo 7'de sunulmuştur.

Tablo 7. Anne Eğitim düzeyi

\begin{tabular}{|l|l|l|l|l|l|}
\hline Varyans Kay. & Kareler Top. & sd & Kareler Ort. & F & p \\
\hline Grup & 375,644 & 4 & 93,911 & 1,129 &, 353 \\
\hline Hata & 4492,932 & 54 & 83,202 & & \\
\hline Toplam & 4868,576 & 58 & & & \\
\hline
\end{tabular}

Year 5/ 2021, Volume-5, Issue-2 | WWW.ispecjournal.org 
Tablo 7'de yer alan Anova testi sonuçlarına göre anne eğitim düzeyi açısından gruplar arasında istatistiksel olarak anlamlı farklılık bulunmadığ 1 tespit edilmiştir. $(F(2,57)=0.112$, p>0.05). Benzer şekilde baba eğitimi faktörünün öğrencilerin bilişim teknolojilerini kullanma düzeylerine etkisinin incelenmesi amaciyla gerçekleştirilen Anova testine yönelik sonuçlar Tablo 8'de sunulmuştur.

Tablo 8. Baba Eğitim Düzeyi

\begin{tabular}{|l|l|l|l|l|l|}
\hline Varyans Kay. & Kareler Top. & sd & Kareler Ort. & F & p \\
\hline Grup & 260,483 & 3 & 86,828 & 1,036 &, 384 \\
\hline Hata & 4608,093 & 55 & 83,784 & & \\
\hline Toplam & 4868,576 & 58 & & & \\
\hline
\end{tabular}

Tablo 8'de yer alan Anova testi sonuçlarına göre baba eğitim düzeyi açısından gruplar arasında istatistiksel olarak anlamlı farklılık bulunmadığı tespit edilmiştir $(F(2,57)=0.112$, $\mathrm{p}>0.05)$.

\section{SONUÇ}

Bilgi ve iletişim çağı olarak adlandırılan 21. Yüz yılda bireylerin teknoloji ile ilgili yeterlik düzeylerinin yükseltilmesi ve öğrencilerin teknolojiyi ihtiyaç duyulan tüm alanlarda kullanmaları gerektiği bilinmektedir (Metin, 2018). Bu bağlamda bu çalışmada ortaokul öğrencilerinin bilişim teknolojilerini kullanma düzeylerinin incelenmesi amaçlanmıştır. Bu amaca yönelik olarak Van ili Erciş ilçesine bağlı bir devlet ortaokulunda 2019-2020 Güz döneminde öğrenim gören 59 öğrencinin bilgi ve iletişim teknolojilerinden yararlanma düzeyleri incelenmiş ve düzeyin $\% 73.3$ oranında olduğu tespit edilmiştir. Araştırma sonuçlarından elde edilen veriler 1şı̆̆ında öğrencilerin bilişim teknolojilerinden büyük oranda yararlandıkları anlaşılmıştır. Araştırmada incelenen diğer faktörler göz önünde bulundurulduğunda cinsiyet değişkeni için, kız öğrencilerin bilişim teknolojilerini kullanma noktasında erkeklerden daha başarılı oldukları söylenebilir. Diğer taraftan katılımcılar sınıf bazında incelendiğinde 6., 7. ve 8. sınıf ortaokul öğrencilerinin bilişim teknolojilerinden yararlanma düzeyleri arasında anlamlı bir fark olmadığı dolayısı ile sınıf faktörünün herhangi bir etkisinin olmadığı görülmektedir. Benzer şekilde ortaokul öğrencilerinin başarı notu ortalamaları dikkate alındığında farklı not gruplarındaki öğrencilerin bilişim teknolojilerinden yararlanma düzeylerinin benzer olduğu görülmüştür. Son olarak ebeveynlerin eğitim düzeyleri ile bilişim teknolojilerini kullanma oranları arasındaki ilişkiler göz önünde 
bulundurulduğunda hem annenin hem de babanın eğitim düzeylerinin bir etkisi bulunmadığ1 anlaşılmıştır.

Elde edilen sonuçlara göre kullanım düzeyi \%73.3 gibi büyük bir oran çıkmasına rağmen günümüz teknolojik imkanları göz önünde bulundurulduğunda bu oranın daha yüksek olması gerektiği söylenebilir. Dolayısı ile öğrencilerin bilişim teknolojilerini kullanma düzeylerinin daha da artırılmasına yönelik adımlar atılması gerektiği anlaşılmaktadır. Ayrıca kız öğrencilerin ölçek puanlarının daha yüksek çıkmasının altında yatan olası sebepler incelenmeli ve gerek görülmesi halinde erkek öğrencilerin teknolojiye yönelik ilgilerini artırabilecek adımlar atılmalıdır. Araştırma pandemi öncesinde toplanan veriler üzerinden gerçekleştirilmiştir. Pandemi sürecinde artan uzaktan eğitim ihtiyacı ile beraber öğrencilerin bilişim teknolojilerinden yararlanma düzeylerinin yeniden gözlemlenerek oluşan fark açığa ç1kartılabilir.

\section{KAYNAKÇA}

Akkoyunlu, B. ve Kurbanoğlu, S. (2003). Öğretmen adaylarının bilgi okuryazarlığı ve bilgisayar öz-yeterlik algıları üzerine bir çalışma. Hacettepe Üniversitesi Ĕ̆itim Fakültesi Dergisi, 24(24). Erişim adresi: https://dergipark.org.tr/en/download/articlefile/87822

Bakioğlu, B. ve Çevik, M. (2020). COVID-19 Pandemisi Sürecinde Fen Bilimleri Öğretmenlerinin Uzaktan eğitime İlişkin Görüşleri. Electronic Turkish Studies, 15(4), 109-129.

Baysan, E., Bayra, E. ve Demirkan, Ö. (2018). Teknoloji destekli işbirliğine dayalı eğitim ortamları araştırmalarına ilişkin içerik analizi (2010-2015). Sakarya Üniversitesi Eğitim Fakültesi Dergisi, (35), 1-22. Erişim adresi: https://dergipark.org.tr/en/pub/sakaefd/issue/38142/270404

Çetin, Y. ve Mirasyedioğlu, Ş. (2019). Teknoloji destekli probleme dayalı öğretim uygulamalarının matematik başarısına etkisi. Journal of Computer and Education Research, 7(13), 13-34. Erişim adresi: https://dergipark.org.tr/en/pub/jcer/issue/44941/494907

Engin, A. O., Tösten, R. ve Kaya, M. D. (2010). Bilgisayar destekli eğitim. Sosyal Bilimler Enstitüsü Dergisi, (5), 69-80. Eşirim Adresi: https://www.kafkas.edu.tr/dosyalar/sobedergi/file/005/6_0.pdf Year 5/ 2021, Volume-5, Issue-2 | WWW.ispecjournal.org 


\section{ISSN 2717-7262 ISPEC Journal of Social Sciences \& Humanities}

Karasar, N. (1999). Bilimsel Araştırma Yöntemi. (9. Basım). Ankara: Nobel Yayın Dağıtım

Metin, E. M. (2018). Eğitimde Teknoloji Kullanımında Öğretmen Eğitimi: Bir Durum

Çalışması. Journal of STEAM Education, 1(1), 79-103. Erişim Adresi :

https://dergipark.org.tr/en/pub/steam/issue/37516/427032

Özmusul, M. (2011). Bilişim teknolojilerinden yararlanma ölçeğinin geliştirilmesi. Kuramsal Eğitimbilim Dergisi, 4(1), 1-17. Erişim Adresi:

https://dergipark.org.tr/en/pub/akukeg/issue/29342/313989

Sarıgöz, O. (2012). Bilgi toplumunun eleştirisi ve Türkiye'de modern eğitimin gerçekleştiremedikleri. Ejovoc (Electronic Journal of Vocational Colleges), 2(1), 72 -

84. Erişim Adresi: https://dergipark.org.tr/en/pub/ejovoc/issue/5394/73161

Yeşilorman, M. ve Firdevs, K.(2014). Bilgi Toplumunun Teknolojik Temelleri Üzerine

Eleştirel Bir Bakış. Fırat Üniversitesi Sosyal Bilimler Dergisi, 24(1), 117-133. Erişim

Adresi: https://dergipark.org.tr/en/pub/firatsbed/issue/17003/177649 